\title{
EDULCORANTES DE ALTA INTENSIDADE: TENDÊNCIAS DE USO EM ALIMENTOS E AVANÇOS EM TÉCNICAS ANALÍTICAS
}

\author{
Ícaro G. Nicolucia, Carolina T. Takehara ${ }^{\mathrm{a}}$ e Adriana P. A. Bragotto ${ }^{\mathrm{a}, *,(1)}$ \\ ${ }^{a}$ Faculdade de Engenharia de Alimentos, Universidade Estadual de Campinas, 13083-862, Campinas - SP, Brasil
}

Recebido em 08/05/2021; aceito em 27/08/2021; publicado na web em 29/09/2021

\begin{abstract}
HIGH-INTENSITY SWEETENERS: TRENDS OF USE IN FOODS AND ADVANCES IN ANALYTICAL TECHNIQUES. The high consumption of sugar by the population and its correlation with the increase in the rates of obesity and chronic non-communicable diseases have promoted discussions of strategies to reduce the intake of this ingredient. In addition to consumer campaigns and governmental public policies, the use of high-intensity sweeteners to replace sugar in foods could be a feasible alternative for reducing sugar intake. However, it is important that high-intensity sweeteners be used considering the maximum permitted levels and approved food categories according to the current legislation. In this context, the development and application of analytical methods to determine high-intensity sweeteners in foods is a current and relevant issue. This manuscript aims to review the general aspects and available analytical techniques for the determination of these additives in food matrices.
\end{abstract}

Keywords: nonnutritive sweeteners; chromatography; food safety; sugar; food additives.

\section{INTRODUÇÃO}

A população brasileira tem adquirido novos hábitos alimentares ao longo dos últimos anos. Pesquisas mostram um aumento na aquisição de alimentos prontos para o consumo e de refeições fora do domicílio por grande parte da população. $\mathrm{O}$ gasto médio mensal em refeições fora do domićlilio aumentou de $31,1 \%$ para $32,8 \%$ segundo comparação entre a Pesquisa de Orçamentos Familiares (POF) 2017 2018 e 2008-2009. ${ }^{1}$ O elevado consumo de sódio, gordura e açúcar tem sido associado a estes novos hábitos alimentares, constituindo fatores preponderantes para desenvolvimento de doenças crônicas não transmissíveis como hipertensão, obesidade e diabetes. ${ }^{2}$

O elevado consumo de açúcar é um fator que contribui para que valores energéticos diários superiores aos recomendados pelas autoridades sanitárias sejam atingidos, sendo que a Organização Mundial da Saúde (OMS) preconiza que seu consumo seja inferior a $10 \%$ da ingestão total de calorias. ${ }^{3}$ Diversas estratégias têm sido propostas pela OMS com a finalidade de atingir esse objetivo, incluindo a realização de campanhas educativas, a taxação de bebidas contendo açúcares adicionados, a restrição de publicidade de alimentos e bebidas ricos em açúcar e a reformulação desses produtos pelas indústrias alimentícias, entre outras. ${ }^{4}$

Visando reduzir o consumo de açúcar pela população brasileira, o Ministério da Saúde firmou, em 2018, um acordo com indústrias alimentícias para redução voluntária do ingrediente em produtos como bebidas açucaradas, biscoitos, bolos, achocolatados e produtos lácteos, tendo como meta uma redução de 144 mil toneladas até o ano de 2022. ${ }^{5}$ Além disso, a Agência Nacional de Vigilância Sanitária (ANVISA) aprovou em 2020 novas regras de rotulagem nutricional, que exigem símbolo informativo de alto teor de açúcar nos rótulos dos produtos para maior conscientização dos consumidores. ${ }^{6}$ Países como a Alemanha, França, México, Portugal e Estados Unidos também realizaram acordos ou utilizaram diferentes estratégias para reduzir o consumo de açúcar de suas populações. ${ }^{7-10}$

Dentro de um contexto com altos índices de obesidade, aumento da prevalência de diabetes e estratégias governamentais para redução do consumo de açúcar e redução de calorias dos alimentos, o uso

*e-mail: pavesi@unicamp.br de edulcorantes, particularmente aqueles classificados como de alta intensidade, representa uma alternativa importante para as indústrias. A legislação vigente no Brasil permite a utilização de 16 diferentes edulcorantes bem como a substituição parcial ou total do açúcar por esses aditivos em alimentos e bebidas para controle de peso, para dietas com ingestão controlada de açúcares, para dietas com restrição de açúcares e produtos com informação nutricional complementar. ${ }^{11}$ Assim, o uso de edulcorantes deve ser feito conforme previsto nos regulamentos, considerando as categorias autorizadas e os limites máximos permitidos, a fim de garantir a segurança do consumidor, uma vez que são substâncias adicionadas intencionalmente aos alimentos. $^{12}$

Dessa forma, diante do atual cenário, observa-se grande relevância na determinação e quantificação dos edulcorantes presentes em alimentos consumidos pela população. Para isso, diversos métodos analíticos têm sido utilizados, permitindo verificar o uso desses ingredientes e o cumprimento das legislações. Esse trabalho tem como objetivo discutir a classificação, características físico-químicas, aspectos regulatórios e o emprego das principais substâncias utilizadas no país, além de revisar o estado-da-arte das estratégias analíticas empregadas para a determinação de edulcorantes de alta intensidade em alimentos e bebidas.

Foi realizada uma busca através das palavras-chave "Sweeteners" e "Nonnutritive sweeteners" no título dos artigos disponíveis nas bases de dados Science Direct e PubMed. As buscas nessas bases de dados geraram 24545 documentos, dos quais 88 artigos científicos publicados entre 1970 e 2021 foram considerados adequados ao tema e utilizados no presente trabalho. Nesta revisão também foram considerados documentos oficiais de agências reguladoras e de comitês científicos internacionais de avaliação do risco.

\section{DEFINIÇÃO, CLASSIFICAÇÃO, ESTRUTURA QUÍMICA E PROPRIEDADES FÍSICO-QUÍMICAS DOS EDULCORANTES}

Os edulcorantes são considerados aditivos alimentares, ou seja, ingredientes que são adicionados intencionalmente a uma formulação sem o intuito de nutrir, e sim de modificar características químicas, físicas, biológicas ou sensoriais de um alimento em etapas de 
processamento, embalagem, transporte ou estocagem. No caso dos edulcorantes, são substâncias diferentes dos açúcares com função de conferir gosto doce ao alimento. ${ }^{13}$

Embora a legislação brasileira ${ }^{11}$ não utilize um sistema de classificação de edulcorantes, é comum encontrar na literatura trabalhos que classificam esses aditivos de três diferentes formas, sendo que cada uma delas utiliza um critério distinto para realizar o agrupamento como mostrado na Figura 1. Primeiramente, os edulcorantes podem ser classificados como edulcorantes nutritivos ou não nutritivos, considerando como critério de agrupamento o fornecimento de calorias pela ingestão, sendo que os nutritivos são capazes de contribuir com valor energético, enquanto os não nutritivos não trazem essa contribuição ou contribuem pouco. Outra forma de classificar os edulcorantes é em relação à sua origem. Nesse caso, as substâncias podem ser classificadas como naturais ou artificiais. ${ }^{14}$ Por fim, existe ainda a forma de classificação que considera o potencial de dulçor do aditivo, sendo considerados de baixa intensidade os que têm capacidade de adoçar igual ou menor que a sacarose, considerada como referência para comparação do poder adoçante, e de alta intensidade os que têm capacidade de adoçar superior a dez vezes à sacarose..$^{15}$

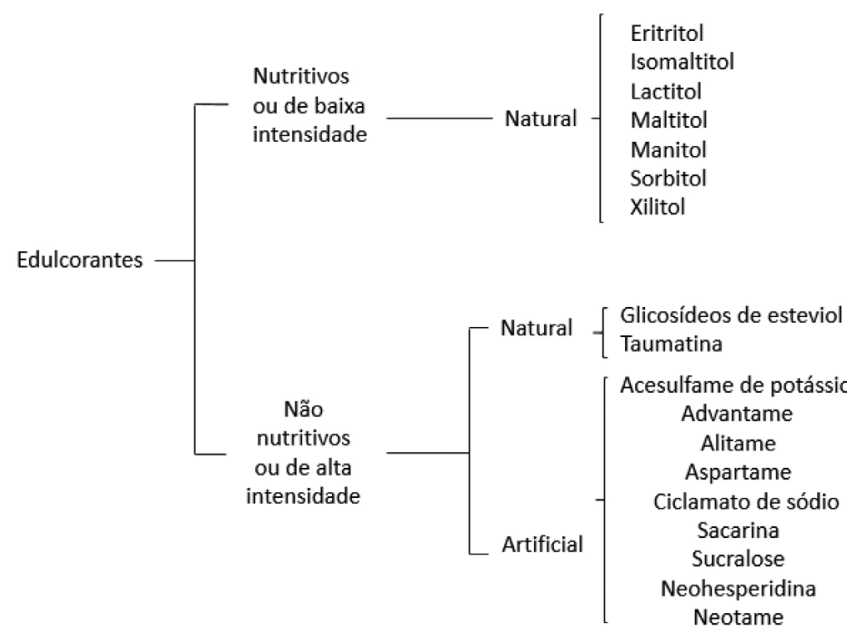

Figura 1. Classificação dos edulcorantes. Adaptado de Daher ${ }^{14}$ e Chakraborty $^{15}$

Devido à sua limitada capacidade de adoçamento, os edulcorantes de baixa intensidade são geralmente utilizados em alimentos e bebidas como estabilizantes, agentes de corpo e espessantes, entre outras funções. ${ }^{16} \mathrm{Já}$ os edulcorantes de alta intensidade são os mais amplamente utilizados para conferir gosto doce. Inicialmente, seu uso era restrito a adoçantes de mesa e refrigerantes sem adição de açúcar, mas atualmente já são empregados em produtos de panificação, cereais, iogurtes, geleias, molhos e condimentos. ${ }^{17} \mathrm{O}$ aumento na diversidade de produtos que contém esses aditivos em sua formulação ocorreu principalmente devido ao alto poder adoçante ${ }^{15}$ como mostrado na Tabela 1.

A estrutura química das moléculas dos edulcorantes de alta intensidade (Figura 2) tem grande importância nas propriedades físico-químicas apresentadas por esses aditivos. A utilização desses edulcorantes nas formulações dos produtos depende de propriedades como a estabilidade em diferentes faixas de temperatura e $\mathrm{pH}$, de forma que as diferentes condições aplicadas durante as etapas de processamento, juntamente com características sensoriais, se tornam fatores decisivos na escolha do edulcorante a ser utilizado no produto. Um exemplo de etapa de processamento comum a diversos alimentos industrializados é o tratamento térmico, que faz com que a estabilidade dos edulcorantes à temperatura tenha grande
Tabela 1. Poder adoçante de edulcorantes de alta intensidade em relação à sacarose $^{18}$

\begin{tabular}{lcc}
\hline Edulcorante & INS & Poder adoçante* \\
\hline Acesulfame de potássio & 950 & $130-200$ \\
Advantame & 969 & 37000 \\
Alitame & 956 & 2000 \\
Aspartame & 951 & 200 \\
Ácido ciclâmico e seus sais & 952 & $30-40$ \\
Glicosídeos de esteviol & 960 & 300 \\
Neohesperidina & 959 & $1500-2000$ \\
Neotame & 961 & $7000-13000$ \\
Sacarina & 954 & $300-500$ \\
Sucralose & 955 & $600-650$ \\
Taumatina & 957 & $600-650$ \\
\hline
\end{tabular}

INS: International Numbering System. *Nessa comparação, a escala de doçura tem como referencial a sacarose com poder adoçante 1 , sendo o potencial de dulçor dos edulcorantes estabelecido em relação a quantas vezes mais doce ou menos doce podem ser em relação à referência. ${ }^{18}$

importância, evitando possíveis degradações do aditivo. ${ }^{19}$ Algumas dessas propriedades estão descritas na Tabela 2.

\section{ASPECTOS REGULATÓRIOS E SEGURANÇA DE USO}

No Brasil, a ANVISA é a agência responsável pela regulamentação de edulcorantes. Está autorizada a utilização de 16 substâncias, incluindo edulcorantes de alta intensidade (acesulfame de potássio; aspartame; ácido ciclâmico e seus sais de cálcio, potássio e sódio; advantame; glicosídeos de esteviol; sacarina e seus sais de cálcio, potássio e sódio; sucralose; taumatina; neotame) e edulcorantes de baixa intensidade (maltitol; isomaltitol; lactitol; xilitol; eritritol; sorbitol; manitol). ${ }^{11}$

Para que aditivos como os edulcorantes sejam autorizados para o consumo, faz-se necessária a realização de uma avaliação que demonstre a sua segurança quanto ao uso pretendido. O Comitê Conjunto FAO/OMS de Especialistas em Aditivos Alimentares (do inglês, Joint FAO/WHO Expert Committee on Food Additives - JECFA) é encarregado de realizar avaliações do risco desses aditivos em âmbito mundial. ${ }^{30}$ Nesta avaliação, são utilizados dados de estudos toxicológicos com animais para determinação do nível sem efeito adverso observado (do inglês, No Observed Adverse Effect Level - NOAEL), que corresponde à maior concentração de determinada substância que não promova efeitos adversos em organismos vivos. A partir dessas informações e aplicando-se um fator de incerteza determina-se a Ingestão Diária Aceitável (IDA), definida como a quantidade de determinada substância que pode ser consumida diariamente ao longo da vida sem oferecer riscos à saúde do consumidor. ${ }^{31}$ Os valores de IDA estabelecidos pelo JECFA para os edulcorantes de alta intensidade autorizados pela ANVISA estão descritos na Tabela 3, bem como as informações provenientes dos estudos toxicológicos utilizados para o estabelecimento desses valores.

Taumatina e os edulcorantes de baixa intensidade em uso no Brasil possuem IDA não especificada, ou seja, os dados (químicos, bioquímicos, toxicológicos e outros) disponíveis no momento da avaliação indicaram que esses aditivos possuem toxicidade muita baixa e que o estabelecimento de uma IDA expressa em forma numérica não era necessário. ${ }^{11}$ Entretanto, vale ressaltar que um consumo excessivo de alguns edulcorantes de baixa intensidade, como o manitol e o eritritol, pode produzir um efeito laxante em seus consumidores. ${ }^{21}$ 


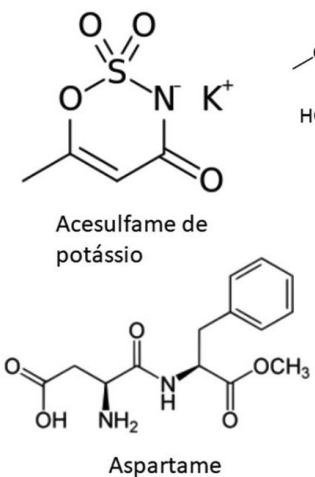<smiles>COC(=O)C(Cc1ccccc1)NC(=O)C(CC(=O)O)NCCCc1ccc(OC)c(O)c1</smiles>

Advantame<smiles>O=[N+]([O-])NS(=O)(=O)NC1CCCCC1</smiles>

Ciclamato de sódio

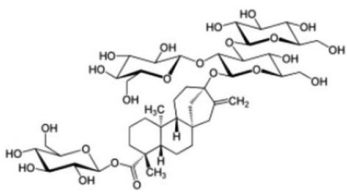

Rebaudiosídeo A<smiles>O=C1NS(=O)(=O)c2ccccc21</smiles>

Sacarina

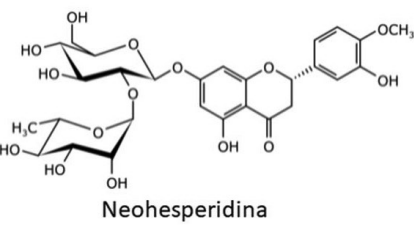

HO<smiles>CCC1OC2(Cl)C(O)C(O)C1C2Cl</smiles>

Sucralose<smiles>C[C@H](NC(=O)[C@H](N)CC(=O)O)C(=O)NC1C(C)(C)SC1(C)C</smiles>

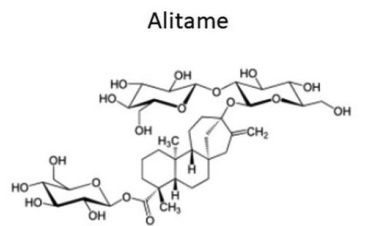

Esteviosídeo<smiles>COC(=O)[C@H](Cc1ccccc1)NC(=O)[C@H](CCNCCC(C)(C)C)NCC(=O)O</smiles>

Figura 2. Estrutura química de edulcorantes de alta intensidade (Imagens: Wikipedia)

Tabela 2. Propriedades físico-químicas de edulcorantes de alta intensidade

\begin{tabular}{|c|c|c|c|c|}
\hline Edulcorante & $\mathrm{pH}$ & Temperatura & Solubilidade em água & $\begin{array}{c}\text { Solubilidade em outros } \\
\text { solventes }\end{array}$ \\
\hline Acesulfame de potássio & $\begin{array}{l}\text { Estável em ampla faixa } \\
\text { de } \mathrm{pH}^{20}\end{array}$ & $\begin{array}{l}\text { Estável a temperatura } \\
\text { ambiente. Decomposição } \\
\text { apenas em temperaturas } \\
\text { muito elevadas acima de } \\
200{ }^{\circ} \mathrm{C}^{19}\end{array}$ & 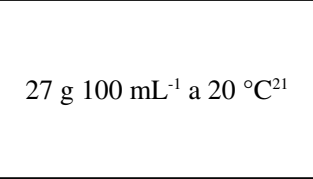 & $\begin{array}{l}\text { Levemente solúvel em } \\
\text { metanol }^{19}\end{array}$ \\
\hline Advantame & Estável em pH ácido ${ }^{22}$ & $\begin{array}{c}\text { Instável em altas } \\
\text { temperaturas, com alto } \\
\text { índice de decomposiçãa }{ }^{23}\end{array}$ & $0,099 \mathrm{~g} \mathrm{~mL}^{-1}$ a $25^{\circ} \mathrm{C}^{22}$ & $\begin{array}{c}\text { Moderadamente solúvel em } \\
\text { etanol }^{19}\end{array}$ \\
\hline Alitame & $\begin{array}{l}\text { Estável em ampla faixa de } \\
\text { pH e máxima estabilidade } \\
\text { em faixa entre } 6-8^{24}\end{array}$ & $\begin{array}{l}\text { Estável em ampla faixa de } \\
\text { temperatura }^{24}\end{array}$ & $0,13 \mathrm{~g} \mathrm{~mL}^{-1} \mathrm{em} \mathrm{pH} 5,6^{24}$ & $\begin{array}{l}\text { Solúvel em álcool e outros } \\
\text { solventes polares }{ }^{24}\end{array}$ \\
\hline Aspartame & $\begin{array}{l}\text { Estável na faixa entre } 3,4 \text { e } \\
5 \text { e máxima estabilidade em } \\
\mathrm{pH} 4,3^{25}\end{array}$ & $\begin{array}{c}\text { Instável em temperaturas } \\
\text { elevadas. Degradação } \\
\text { de } 40 \% \text { a } 90^{\circ} \mathrm{C} \text { por } \\
20 \text { minutos e completa } \\
\text { degradação a } 120^{\circ} \mathrm{C} \text { por } \\
15 \text { minutos }{ }^{26} \\
\end{array}$ & 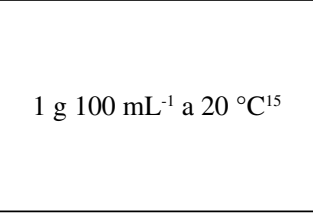 & $\begin{array}{c}\text { Moderamente solúvel em } \\
{\text { álcool }{ }^{19}}^{19}\end{array}$ \\
\hline Ciclamato de sódio & $\begin{array}{l}\text { Estável em faixa 2-10 de } \\
\mathrm{pH}^{21}\end{array}$ & $\begin{array}{l}\text { Estável em ampla faixa de } \\
\text { temperatura }^{21}\end{array}$ & 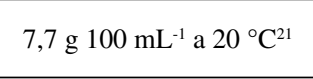 & Solúvel em propilenoglicol ${ }^{22}$ \\
\hline Glicosídeos de esteviol & $\begin{array}{c}\text { Estável na faixa entre } 2,5 \\
\text { e } 9^{27}\end{array}$ & $\begin{array}{c}\text { Estável em altas } \\
\text { temperaturas }\left(100^{\circ} \mathrm{C}\right)^{27}\end{array}$ & $0,125 \mathrm{~g} \mathrm{~mL}^{-1}$ a $20^{\circ} \mathrm{C}^{21}$ & Solúvel em etanol ${ }^{27}$ \\
\hline Neohesperidina & $\begin{array}{c}\text { Estável em faixa 2-6 de } \\
\mathrm{pH}^{24}\end{array}$ & $\begin{array}{c}\text { Estável em altas } \\
\text { temperaturas }\left(130^{\circ} \mathrm{C}\right)^{24}\end{array}$ & $0,005 \mathrm{~g} \mathrm{~L}^{-1}$ a $20{ }^{\circ} \mathrm{C}^{24}$ & $\begin{array}{l}\text { Moderadamente solúvel em } \\
\text { etanol }^{24}\end{array}$ \\
\hline Neotame & $\begin{array}{c}\text { Estável em faixa de } \mathrm{pH} \\
\text { entre } 3 \text { e } 7 \text { e pH ótimo em } \\
4,5^{28}\end{array}$ & Estável até $80^{\circ} \mathrm{C}^{28}$ & $1,3 \mathrm{~g} \mathrm{~mL}^{-1}$ a $20^{\circ} \mathrm{C}^{21}$ & Solúvel em etanol ${ }^{19}$ \\
\hline Sacarina & $\begin{array}{l}\text { Estável em ampla faixa } \\
\text { de } \mathrm{pH}^{19}\end{array}$ & $\begin{array}{c}\text { Estável em ampla faixa de } \\
\text { temperatura }^{19}\end{array}$ & $0,32 \mathrm{~g} \mathrm{~mL}^{-1}$ a $20^{\circ} \mathrm{C}^{21}$ & $\begin{array}{c}\text { Moderadamente solúvel em } \\
\text { etanol }^{19}\end{array}$ \\
\hline Sucralose & $\begin{array}{c}\text { Estável em faixa de } \mathrm{pH} \\
\text { entre } 3 \text { e } 7^{26}\end{array}$ & Estável até $100^{\circ} \mathrm{C}^{28}$ & 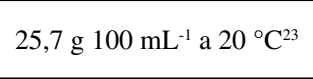 & Solúvel em etanol ${ }^{21}$ \\
\hline Taumatina & $\begin{array}{l}\text { Estável em faixa de } \mathrm{pH} \\
\quad \text { entre } 2,7 \text { e } 6^{24}\end{array}$ & $\begin{array}{l}\text { Estável em altas } \\
\text { temperaturas }^{29}\end{array}$ & $0,6 \mathrm{~g} \mathrm{~mL}^{-1.21}$ & $\begin{array}{c}\text { Moderadamente solúvel em } \\
\text { etanol }^{24}\end{array}$ \\
\hline
\end{tabular}


Tabela 3. Ingestão Diária Aceitável para os edulcorantes de alta intensidade autorizados no Brasil ${ }^{32}$

\begin{tabular}{|c|c|c|c|c|}
\hline Edulcorante & NOAEL (mg/kg pc) & Fator de incerteza & Espécie & IDA $(\mathrm{mg} / \mathrm{kg} \mathrm{pc})$ \\
\hline Acesulfame de potássio & 1500 & 100 & Rato & 15 \\
\hline Advantame & 500 & 100 & Coelho & 5 \\
\hline Aspartame & 4000 & 100 & Rato & 40 \\
\hline Ácido ciclâmico e seus sais & 1058 & 100 & Rato & 11 \\
\hline Glicosídeos de esteviol* & 383 & 100 & Rato & 4 \\
\hline Neotame & 200 & 100 & Cachorro & 2 \\
\hline Sacarina & 500 & 100 & Rato & 5 \\
\hline Sucralose & 1500 & 100 & Rato & 15 \\
\hline
\end{tabular}

Taumatina

IDA: Ingestão diária aceitável (Estabelecidas pelo JECFA - Joint FAO/WHO Expert Committee on Food Additives). NOAEL: No Observed Adverse Effect Level. Pc: peso corpóreo. *Expresso em equivalente de esteviol.

Com base nos resultados desta avaliação, as agências reguladoras de cada país responsáveis pela regulamentação de aditivos como os edulcorantes autorizam seu uso e definem em quais categorias de alimentos poderão ser empregados, além de estabelecer os limites máximos permitidos. ${ }^{19}$ A Tabela 4 apresenta os limites permitidos dos edulcorantes de alta intensidade autorizados no Brasil, assim como informações provenientes dos EUA, Europa, Japão e Codex Alimentarius para comparação.

Os limites mostrados na Tabela 4, definidos pelas diferentes agências reguladoras, apresentam um intervalo decorrente dos diferentes produtos nos quais a utilização dos edulcorantes é permitida. Diferentes categorias de alimentos apresentam diferentes limites permitidos para cada substância. A legislação dos Estados Unidos, por exemplo, não define os limites permitidos para os edulcorantes descritos na Tabela 4, com exceção da sacarina, nas diferentes categorias de alimentos. ${ }^{33} \mathrm{O}$ Japão também não define os limites permitidos para alguns edulcorantes, de forma que os classifica como aditivos que não necessitam de limites. ${ }^{35}$

Países como Estados Unidos e Japão não permitem o uso de ácido ciclâmico e seus sais (ciclamato) em alimentos e bebidas. Nos Estados Unidos, essa proibição ocorreu em 1969 em função de resultados de estudos que mostravam que misturas de ciclamato e sacarina, na proporção de 10:1, induziam o desenvolvimento de câncer de bexiga. ${ }^{36}$ Embora o ciclamato já tenha sido considerado seguro em estudos mais recentes, este edulcorante ainda é proibido nos países mencionados. ${ }^{33,35}$ A autorização de uso do ciclamato no Brasil é respaldada pela sua principal referência internacional, o Codex Alimentarius, sendo o uso deste edulcorante previsto na Norma Geral de Aditivos Alimentares (do inglês, General Standard for Food Additives - GSFA). ${ }^{37}$

No Brasil, a taumatina e os edulcorantes de baixa intensidade, que possuem IDA não especificada, devem ser usados de acordo com as Boas Práticas de Fabricação (BPF), ou seja, no menor nível necessário para alcançar o efeito tecnológico desejado, sendo indicados na legislação nacional como quantum satis. ${ }^{30}$

Apesar de terem seu uso aprovado por inúmeras autoridades sanitárias ao redor do mundo, os edulcorantes estão constantemente envolvidos em estudos polêmicos relacionando seu consumo a doenças e efeitos adversos à saúde. Diversos trabalhos foram publicados mostrando possíveis relações entre o consumo de edulcorantes e alterações na microbiota intestinal, aumento do risco de desenvolvimento de diabetes tipo 2 e aumento do risco de desenvolvimento de câncer. ${ }^{36,38,39}$ Outros autores indicaram associação entre o consumo de edulcorantes por crianças com um aumento no índice de massa corpórea, mas não com outros distúrbios metabólicos como aumento da gordura corporal e desenvolvimento de diabetes tipo $2 .^{40}$

Com base em uma revisão das evidências clínicas disponíveis até o momento, Ashwell et al. concluíram que estes estudos não sugerem motivos para preocupações sobre os efeitos adversos dos

Tabela 4. Limites máximos permitidos de edulcorantes de alta intensidade pelo Codex Alimentarius, Brasil, EUA, Europa e Japão

\begin{tabular}{|c|c|c|c|c|c|}
\hline \multirow{2}{*}{ Edulcorante } & \multicolumn{5}{|c|}{ Limite permitido (g/100 g ou $100 \mathrm{~mL}$ ) } \\
\hline & Codex $^{32}$ & Brasi $^{11}$ & EUA $^{33}$ & Europa $^{34}$ & Japão $0^{35}$ \\
\hline Acesulfame de potássio & $0,011-0,5$ & $0,026-0,5$ & ND & $0,0025-0,25$ & $0,035-1,5$ \\
\hline Advantame & SP & $0,00375-0,04$ & ND & $0,00005-0,04$ & ND \\
\hline Aspartame & $0,004-0,03$ & $0,056-1,0$ & ND* & $0,0025-0,6$ & ND \\
\hline Ácido ciclâmico e seus sais & $0,03-1,0$ & $0,03-0,075$ & $\mathrm{NP}$ & $0,025-0,125$ & NP \\
\hline Glicosídeos de esteviol & $0,025-0,3$ & $0,045-0,24$ & ND & $0,02-0,33$ & ND \\
\hline Neotame & $0,03-0,35$ & $0,0033-0,1$ & ND & $0,0001-0,025$ & ND \\
\hline Sacarina & $0,008-0,25$ & $0,01-0,12$ & $* *$ & $0,005-0,3$ & $0,01-0,2$ \\
\hline Sucralose & $0,001-0,1$ & $0,02-0,3$ & ND & $0,001-0,24$ & $0,04-1,2$ \\
\hline Taumatina & Quantum satis & Quantum satis & $\mathrm{NP}$ & $0,005-0,04$ & ND \\
\hline
\end{tabular}

ND: não definido (deve ser usado de acordo com as Boas Práticas de Fabricação). NP: não permitido. SP: sem provisão. Codex Alimentarius ${ }^{32}$ ANVISA; ${ }^{11}$ FDA $;{ }^{33}$ EC $;{ }^{34}$ JETRO.$^{35}$ Glicosídeos de esteviol expressos em equivalente de esteviol pelo Codex Alimentarius ${ }^{32}$ e EC. ${ }^{34} *$ Quando o aspartame é usado em produtos de panificação e misturas de panificação, a quantidade do aditivo não deve exceder 0,5 por cento em peso de produtos prontos para assar ou de formulações acabadas antes de assar. **Em bebidas, sucos de frutas e bases ou misturas, quando preparadas para consumo de acordo com as instruções, em quantidades não superiores a 12 miligramas do aditivo, calculado como sacarina, por onça líquida. Em alimentos processados, em quantidades não superiores a 30 miligramas do aditivo, calculado como sacarina, por porção de tamanho designado. 
edulcorantes na preferência por doces, apetite ou controle da glicose, sendo que essas substâncias podem melhorar o controle do diabetes e a adequação dietária. Com relação aos efeitos sobre a microbiota intestinal humana, os dados são limitados e não fornecem evidências adequadas de que os edulcorantes afetem a saúde intestinal em doses relevantes para uso humano. Os autores também concluíram que os edulcorantes de alta intensidade podem ser benéficos para o controle de peso quando usados para substituir o açúcar em produtos consumidos na dieta (sem substituição de energia). ${ }^{41}$

No contexto de segurança de uso dos edulcorantes, é importante garantir que a exposição dos consumidores a estas substâncias esteja abaixo da IDA. Uma revisão global dos estudos sobre ingestão de edulcorantes realizados de 2008 a 2018 foi publicada por Martyn et al. Os autores coletaram informações reportadas por países da Europa, Ásia e América Latina, além da Austrália. No geral, os estudos conduzidos não levantaram preocupações com relação a uma exposição acima da IDA. Ademais, os dados avaliados não sugerem um aumento na exposição ao longo do tempo, com vários indicando inclusive uma redução na ingestão. No entanto, alguns dados sugerem que pode ter havido um aumento no número de consumidores de produtos adoçados com edulcorantes de alta intensidade. ${ }^{42}$

No Brasil são escassos os dados de ingestão de edulcorantes. Quatro estudos realizados no país foram responsáveis por estimar a ingestão da população brasileira com base em hábitos alimentares locais. ${ }^{43-46} \mathrm{O}$ estudo mais recente, realizado no ano de 2020, utilizou informações de consumo de alimentos e bebidas da POF 2008-2009 juntamente com informações fornecidas por diversas indústrias em relação às quantidades de edulcorantes adicionadas para estimar a ingestão de acesulfame de potássio, aspartame, ciclamato, sacarina, glicosídeos de esteviol e sucralose pela população brasileira. Os autores observaram que as estimativas de ingestão para os seis edulcorantes não atingiram as suas respectivas IDAs. ${ }^{46}$

\section{EDULCORANTES EM ALIMENTOS}

A crescente procura dos consumidores por produtos com teores reduzidos de açúcares, o acordo firmado com o governo brasileiro para redução voluntária deste ingrediente em alimentos industrializados e a nova legislação da ANVISA têm incentivado a reformulação de diversos produtos já comercializados. Espera-se que, nos próximos anos, uma maior variedade de alimentos contendo edulcorantes esteja disponível no mercado, assim como já vem sendo observado em outros países, não apenas em produtos dietéticos, mas também em produtos regulares. Em Portugal, por exemplo, após a aprovação da taxação de bebidas açucaradas em 2017, observou-se a diminuição dos açúcares adicionados em refrigerantes e aumento de produtos que promoveram sua substituição por ciclamato, sucralose e glicosídeos de esteviol, resultando em uma redução de $50 \%$ na ingestão de açúcar pelo consumo de bebidas que apresentavam concentrações de açúcar superiores a $80 \mathrm{~g} \mathrm{~L}^{-1} .{ }^{9}$ Os Estados Unidos utilizaram a mesma estratégia para redução do consumo de açúcar, aprovando a taxação a bebidas açucaradas, o que resultou em um aumento de $16 \%$ no consumo de edulcorantes. ${ }^{10}$

Segundo a Associação Brasileira da Indústria de Alimentos para Fins Especiais e Congêneres (ABIAD), aproximadamente 35\% da população em geral consome algum tipo de produto dietético, sendo o refrigerante zero o mais consumido.$^{47}$ Em estudo com 120 pacientes diabéticos atendidos pelo Sistema Único de Saúde (SUS) em Ribeirão Preto - SP, foi relatado que a gelatina era o segundo produto diet mais consumido, sendo ultrapassado apenas pelo refrigerante. ${ }^{48}$

Petrarca et al. promoveram um estudo que teve como objetivo determinar os teores de ciclamato de sódio nos refrigerantes de baixa caloria mais consumidos dos mercados brasileiros. Das 18 amostras de refrigerantes analisadas, dos tipos cola, guaraná, laranja, limão e uva, oito apresentaram teor de ciclamato de sódio abaixo de $75 \mathrm{mg}$ $100 \mathrm{~mL}$, limite máximo estabelecido pela legislação brasileira para bebidas não alcoólicas gaseificadas e não gaseificadas. Os valores médios obtidos entre duas amostras de diferentes lotes do mesmo produto variaram entre 27,1 e $127,3 \mathrm{mg} 100 \mathrm{~mL}^{-1}$. Além disso, todas as amostras de refrigerantes apresentaram teores de ciclamato de sódio superiores àqueles indicados em seu rótulo. ${ }^{49}$

Pane et al. realizaram a determinação de diversos edulcorantes presentes em 45 amostras de alimentos classificadas como diet, light e zero, adquiridas em mercados das cidades de Campinas e São Paulo. Refrigerantes, néctares de frutas, achocolatados em pó, molhos barbecue e de tomate foram alguns dos alimentos analisados. Para as amostras de refrigerante, os edulcorantes mais frequentemente encontrados foram o aspartame e o acesulfame de potássio, sendo que nenhuma delas apresentou teores acima dos limites legais. Uma das marcas de refrigerante de limão apresentou quantidade de acesulfame de potássio superior em $29 \%$ ao declarado em seu rótulo, enquanto uma marca de refrigerante de guaraná apresentou $19 \%$ a mais de ciclamato em relação ao declarado no rótulo. Em amostras de gelatina, os autores observaram somente a presença de aspartame, mesmo que outros edulcorantes tenham sido declarados no rótulo, como acesulfame de potássio, ciclamato de sódio e sacarina. Os teores de aspartame estavam de acordo com a legislação vigente. Amostras de néctar de frutas e achocolatado em pó apresentaram majoritariamente a adição de acesulfame de potássio e os limites definidos pela legislação foram respeitados. Em amostras de molho de tomate e de molho barbecue foi encontrado apenas o acesulfame de potássio, sendo que os valores reportados superaram o limite permitido pela legislação em 4 e 7 vezes, respectivamente. Esses resultados reforçam a necessidade de monitorar efetivamente a adição de edulcorantes e comparar com o valor declarado no rótulo e com os limites máximos permitidos, contribuindo para a segurança dos alimentos. ${ }^{50}$

Visando a redução do açúcar em diversos alimentos, misturas de tagatose e glicosídeos de esteviol apresentaram características sensoriais favoráveis para aplicação em refrigerantes, conferindo sabor agradável, redução de sabor residual e boa estabilidade. ${ }^{51}$ Vale ressaltar que o Ministério da Agricultura, Pecuária e Abastecimento (MAPA) passou a permitir desde 2015 a fabricação de bebidas como refrigerantes, refrescos e xaropes com mistura de açúcar e edulcorantes, como uma ação emergencial, visando à redução parcial do conteúdo de açúcar desses produtos. ${ }^{52}$

Inúmeras estratégias têm sido utilizadas para a redução do açúcar nos produtos lácteos, como a hidrólise da lactose, ultrafiltração, redução direta e a substituição por edulcorantes. Destaca-se a última, uma vez que essa apresenta uma redução de calorias sem que haja alteração na doçura. Para isso, deve-se ter em vista a especificidade exigida por cada produto lácteo, a fim de adquirir características sensoriais agradáveis e semelhantes ao original. A substituição do açúcar foi realizada com êxito em alguns produtos como iogurtes, sorvetes e leites aromatizados. ${ }^{53}$

Em estudo realizado por Lin \& Lee, a substituição de $80 \%$ da sacarose por dextrina e sucralose resultou num bolo Chiffon com menor volume e maior dureza, devido ao aumento da temperatura de gelatinização do amido, que provocou a diminuição da viscosidade da massa durante o assamento e, consequentemente, a redução da capacidade de retenção de água. ${ }^{54}$ Embora a sucralose promova menor volume em pães e bolos, ela ainda é muito utilizada na panificação, principalmente em biscoitos, em virtude de sua excelente estabilidade térmica e molecular, que evita a interação química com outros ingredientes. ${ }^{55}$ Silva et al. ainda ressaltaram, a partir dos resultados de seu experimento, que os biscoitos elaborados com sucralose superaram a aceitação em relação à formulação convencional, contendo açúcar. ${ }^{56}$ 
Apesar de parecer simples, o desenvolvimento de formulações de produtos de panificação com redução ou a substituição de açúcares, por exemplo, tornou-se um desafio tecnológico, pois o açúcar é um ingrediente que lhes conferem características fundamentais, como textura, maciez, sabor e conservação. ${ }^{57-59}$

Alguns estudos foram realizados no Brasil para verificação da presença de edulcorantes em diversos alimentos disponíveis comercialmente através de seus rótulos. Figueiredo et al. analisaram um total de 4539 amostras de alimentos de diversas categorias e observaram a presença de pelo menos um edulcorante em 602 amostras. Os produtos que apresentaram mais amostras contendo edulcorantes em relação ao total verificado para a mesma categoria foram: bebidas em pó (100\%), bolo com recheio e cobertura (87,5\%), geleias $(85,5 \%)$, bolo sem recheio ou cobertura $(71,4 \%)$, kani-kama $(66,6 \%)$, gomas de mascar $(60,0 \%)$ e refrigerantes $(50 \%)$. Dentre as amostras que continham edulcorantes, observou-se maior prevalência do acesulfame de potássio (20\% das amostras) e sucralose (16,8\% das amostras). Os edulcorantes menos utilizados foram os polióis, incluindo o xilitol, e neotame. ${ }^{60}$ Oliveira et al. também realizaram a análise do rótulo de 117 bebidas alcoólicas e não alcoólicas para verificar a presença de diferentes aditivos, entre eles, os edulcorantes. Foram encontrados diversos edulcorantes nas 60 amostras de bebidas não alcoólicas, sendo principalmente a sucralose e o acesulfame de potássio, estando presentes, respectivamente, em 16 e 15 amostras de bebidas como sucos de fruta, bebidas à base de soja, refrigerantes e chás. ${ }^{61}$

Em geral, observa-se que o uso de misturas de edulcorantes é uma prática comum na indústria, buscando um efeito sinérgico que promova uma melhor qualidade sensorial do alimento, além de reduzir o consumo de açúcar e de minimizar a possibilidade de a IDA ser ultrapassada. ${ }^{62}$ A utilização de acesulfame de potássio com sucralose ou aspartame é capaz de mascarar o sabor residual de ambos e ainda possui efeito sinérgico capaz de aumentar o poder adoçante da mistura, tornando-se uma boa alternativa para diversos alimentos. ${ }^{15} \mathrm{~A}$ mistura de ciclamato e sacarina também é amplamente aplicada em alimentos. O ciclamato é capaz de inibir receptores gustativos que permitem a percepção de gosto amargo da sacarina e, assim, promovem uma melhora sensorial e melhor aceitação pelos consumidores. ${ }^{63}$

\section{MÉTODOS ANALÍTICOS}

De forma a identificar as principais tendências de uso de edulcorantes de alta intensidade em alimentos, inclusive como estratégia para redução de açúcares adicionados nos produtos industrializados, bem como de verificar o atendimento à legislação vigente, o emprego de métodos analíticos capazes de determinar simultaneamente, com precisão e exatidão, diferentes substâncias, torna-se fundamental. Esse conhecimento é essencial para garantir a segurança dos alimentos consumidos pela população. ${ }^{50}$ As principais técnicas analíticas reportadas na literatura utilizadas para este fim estão resumidas na Figura 3 e serão discutidas a seguir.

\section{Cromatografia}

A cromatografia é uma das técnicas mais utilizadas para a análise de alimentos, sendo amplamente empregada na quantificação de aditivos como os edulcorantes. A complexidade das matrizes faz com que seja necessário otimizar a seletividade através da escolha de fases móvel e estacionária adequadas. Essa otimização permite que diversos edulcorantes sejam determinados de forma simultânea, tornando o método muito útil principalmente para alimentos que contenham misturas de edulcorantes. ${ }^{64}$

\section{Cromatografia líquida}

A cromatografia líquida de alta eficiência (CLAE) [do inglês, High Performance Liquid Chromatography - HPLC ou Ultra-High Performance Liquid Chromatography - UHPLC (quando se utiliza colunas cromatográficas de partículas de dimensão sub- $2 \mu \mathrm{m}$, ou seja, partículas de diâmetro inferior a 2 microns) $]^{65}$ é a técnica mais utilizada para a determinação de diversos edulcorantes em alimentos.

A determinação de aspartame, sacarina e sucralose em bebidas pôde ser realizada através de cromatografia líquida acoplada a espectrômetro de massas (do inglês, Liquid Chromatography coupled to Mass Spectrometry - LC-MS) com analisador por de tempo de voo (do inglês, Time of Flight - ToF) conforme reportado em 2010 por um estudo conduzido nos EUA. As amostras foram filtradas em membrana para a eliminação de partículas e utilizou-se coluna de fase reversa $\mathrm{C} 8$ e eluição gradiente com acetonitrila e água, ambos com ácido fórmico, demonstrando alta seletividade do método analítico. ${ }^{66}$

Em 2013, uma pesquisa realizada em Portugal avaliou a presença de ciclamato de sódio em amostras de adoçantes de mesa líquido e em pó através de CLAE, após derivatização do analito em N,Ndiclorociclohexilamina e diluição em n-heptano. A detecção foi realizada em espectrofotômetro de ultravioleta (UV) em comprimento de onda de $314 \mathrm{~nm}$. Utilizou-se coluna de fase reversa e eluição isocrática com água e metanol para a eluição do analito. ${ }^{67}$

Métodos baseados em cromatografia líquida acoplada a

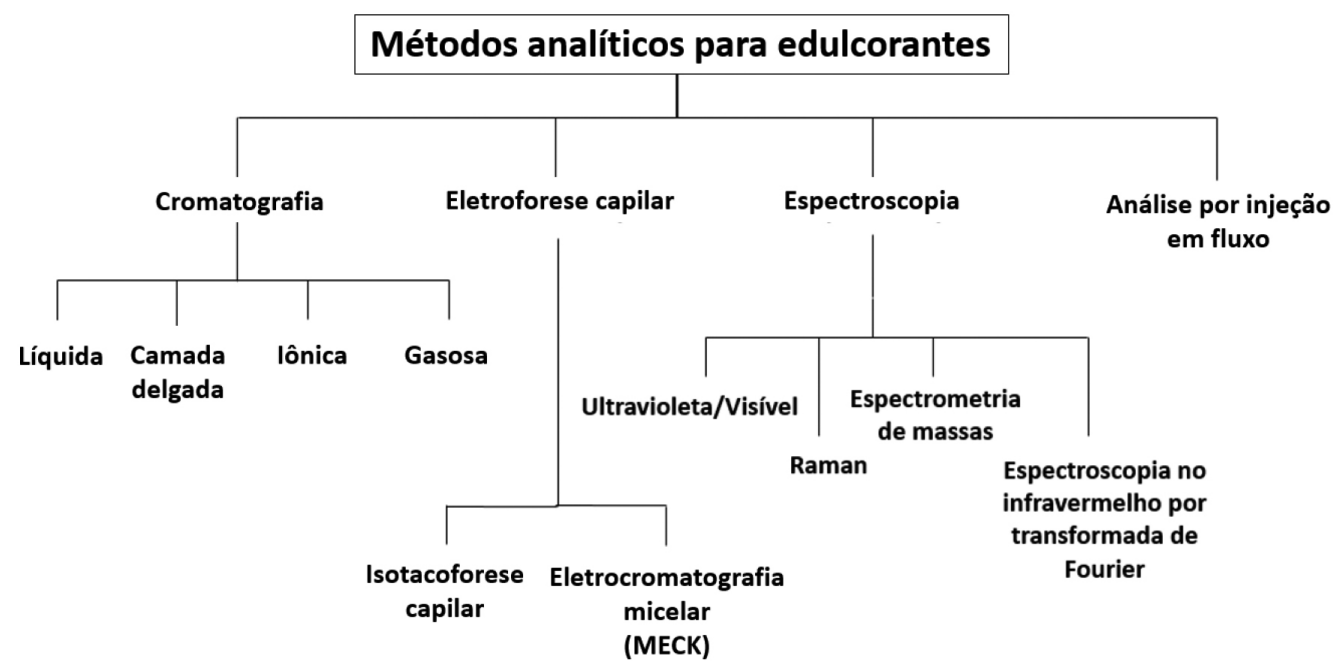

Figura 3. Métodos analíticos utilizados para determinação de edulcorantes 
espectrometria de massas sequencial (LC-MS/MS) e acoplada a detector por espalhamento de luz evaporativo (LC-ELSD) (do inglês, Evaporative Light Scattering Detector - ELSD) se mostraram eficientes na determinação de vários edulcorantes de forma simultânea. Através da técnica de LC-MS/MS, descrita em trabalho publicado em 2014, foi possível determinar a concentração de 10 edulcorantes de alta intensidade presentes em alimentos disponíveis em Taiwan. O preparo da amostra baseou-se na sua diluição com água deionizada seguida de filtração antes da injeção no equipamento. Uma coluna de fase reversa fenil-hexil e fase móvel composta de água deionizada/acetato de amônio e metanol/acetato de amônio com eluição gradiente foram utilizadas. ${ }^{68}$ Através de LCELSD, determinou-se nove edulcorantes presentes em refrigerantes, energéticos, sucos de fruta e iogurtes disponíveis na Bélgica com etapa prévia de extração em fase sólida das amostras utilizando metanol e solução tampão e separação cromatográfica em coluna de fase reversa, conforme estudo publicado em 2007. ${ }^{69}$ Ambos os métodos analíticos descritos conseguiram analisar o ciclamato de sódio sem a necessidade de derivatização, situação comum para analitos com ausência de cromóforos que absorvam no UV. ${ }^{68,69}$

Em 2021, pesquisadores da Turquia reportaram a determinação simultânea de sete edulcorantes (acesulfame de potássio, sacarina, aspartame, alitame, neohesperidina, rebaudiosídeo A e sucralose) em diversos alimentos através de CLAE com detector de arranjo de diodos (do inglês, Diode Array Detector - DAD). As amostras foram analisadas utilizando coluna core-shell com camada de sílica porosa como fase estacionária e fase móvel composta por acetonitrila, tampão fosfato e água, permitindo comparar os resultados com as legislações vigentes. ${ }^{70}$

Em comparação com HPLC, UHPLC apresenta maior velocidade de análise, maior detectabilidade e sensibilidade, fornecendo sinais analíticos mais intensos e maior eficiência de separação entre os analitos, também sendo amplamente utilizada para determinação de edulcorantes. ${ }^{71,72} \mathrm{Em} 2015$, a UHPLC acoplada a detector de arranjos de diodo (UHPLC-DAD) e a acoplada a espectrômetro de massas sequencial (UHPLC-MS/MS) foram reportadas para a determinação de sete e 10 edulcorantes de alta intensidade presentes em bebidas do Japão e Espanha, respectivamente. Ambas utilizaram coluna de fase reversa $\mathrm{C} 18$ e fase móvel composta por acetonitrila e ácido fórmico ou tampão fosfato, demostrando grande eficiência em análises quantitativas. $^{73,74}$

A determinação de nove edulcorantes de alta intensidade em bebidas como refrigerantes e néctares de frutas disponíveis no comércio da Espanha foi descrita em 2014 através da utilização de LC-MS empregando altas temperaturas na coluna cromatográfica. O preparo da amostra consistiu em degaseificação das mesmas através da utilização de banho ultrassônico, diluição em água ultrapura e filtração antes da injeção. As condições utilizadas para separação envolveram temperaturas entre $110^{\circ} \mathrm{C}$ e $150{ }^{\circ} \mathrm{C}$ e eluição gradiente com acetato de amônio e etanol. Essa técnica mostrou-se uma boa opção às técnicas clássicas de cromatografia líquida e utilizou fases móveis ambientalmente amigáveis. ${ }^{75}$

LC-MS/MS utilizando coluna de interação hidrofílica (do inglês, Hydrophilic Interaction Chromatography - HILIC) também foi descrita na literatura em 2016 para determinação de oito edulcorantes de alta intensidade presentes em bebidas alcoólicas e não alcoólicas e também em sucos instantâneos em pó disponíveis em comércios da Polônia. ${ }^{76}$ Nesse caso, o preparo de amostras consistiu em banho ultrassônico para degaseificação das mesmas e diluição com acetonitrila antes da injeção. Por se tratar de uma fase estacionária que utiliza fase móvel hidrofílica (uma vez que se assemelha à cromatografia em "fase normal"), a fase móvel empregada é composta de um eluente contendo água (tampão, por exemplo) e elevada concentração de solvente orgânico que apresente miscibilidade com água. ${ }^{77}$ Assim, no caso do trabalho mencionado, foi utilizado $96 \%$ de acetonitrila e 4\% de tampão acetato de amônio de composição inicial, empregando eluição gradiente até atingir 50\% de acetonitrila. Esse tipo de separação apresentou melhores resultados para os glicosídeos de esteviol quando comparado com a cromatografia líquida em fase reversa, porém não se mostrou tão eficiente para compostos iônicos como o acesulfame de potássio, que necessita de $\mathrm{pH}$ inferior a 3 para separação cromatográfica, sendo que a HILIC utiliza pH por volta de $6 .^{76}$

\section{Cromatografia em camada delgada}

A utilização da cromatografia em camada delgada (do inglês, Thin Layer Chromatography - TLC) se mostrou uma alternativa a técnicas mais sofisticadas e de alto custo, podendo ser utilizada para a determinação de edulcorantes. Pesquisadores poloneses utilizaram placa revestida com sílica gel com fase móvel composta por etanol, isopropanol e amônia aquosa para determinação de edulcorantes (acesulfame de potássio, aspartame, ciclamato de sódio) e conservador (ácido benzóico) em refrigerantes e sucos, de acordo com um trabalho publicado em 2004. ${ }^{78}$ Em estudo mais recente, realizado em 2018, quatro edulcorantes (acesulfame de potássio, aspartame, sacarina e neohesperidina) e oito corantes presentes em balas, geleias e sucos disponíveis em comércios locais da Índia foram determinados por essa técnica. As amostras foram diluídas em água e também utilizouse placa revestida com sílica gel, porém com acetonitrila como fase móvel sendo que a separação foi realizada em 20 minutos. $^{79}$

\section{Cromatografia iônica}

Dois métodos foram utilizados para separação de quatro edulcorantes (acesulfame de potássio, aspartame, ciclamato de sódio e sacarina sódica), presentes em bebidas como refrigerantes, sucos e frutas em conserva disponíveis em comércios da China, baseados na utilização da cromatografia iônica (do inglês, Ion Chromatography IC). Um deles, publicado em 1997, utilizou detector UV combinado com detector de condutividade e eluição gradiente com diferentes concentrações de carbonato de sódio ${ }^{80}$ e o mais recente, publicado em 2005, detector de supressão de condutividade e gerador de eluente hidróxido de potássio. ${ }^{81}$ Ambas as metodologias realizaram uma etapa de preparo de amostra composta por diluição em água deionizada seguido de filtração e se mostraram efetivas na determinação desses edulcorantes de forma simultânea, mas não foram aplicadas a outros edulcorantes, que possivelmente tenham como característica não serem ionizáveis. ${ }^{80,81}$

\section{Cromatografia gasosa}

Embora a cromatografia gasosa (do inglês, Gas Chromatography - GC) seja raramente usada hoje para a análise de edulcorantes devido à baixa volatilidade dos compostos e dificuldade de formar derivados voláteis, ${ }^{82}$ alguns trabalhos encontram-se publicados na literatura utilizando essa técnica analítica. Determinações qualitativa e quantitativa de sucralose em adoçante de mesa do mercado chinês puderam ser realizadas por GC acoplada à espectrometria de massas (GC-MS) e a detector por ionização de chama (GC-FID) (do inglês, Flame Ionization Detector - FID), respectivamente, após conversão do analito em seu éter trimetilsilil (TMS), conforme trabalho publicado em $2007 .{ }^{83}$

Em estudo de 2011, realizado no Irã, o ciclamato de sódio também foi determinado por GC-FID em adoçante de mesa, refrigerante e suco de fruta após microextração em gota única em espaço confinado (do inglês, Headspace Single Drop Microextraction - HS-SDME). O procedimento foi baseado na reação do ciclamato com nitrito em meio levemente ácido e extração do ciclohexeno formado em uma microgota 
para injeção direta no cromatógrafo. Entre os solventes de extração testados, n-dodecano proporcionou a melhor eficiência de extração. De acordo com os autores, o método desenvolvido é simples, rápido, barato, preciso e notavelmente livre de efeitos de interferência. ${ }^{84}$

Também na China, um método baseado em cromatografia gasosa acoplada a detector de captura de elétrons (GC-ECD) (do inglês, Electron Capture Detector - ECD) foi reportado no ano de 2012 para a determinação de ciclamato de sódio em alimentos e bebidas, após a conversão do analito em N,N-diclorociclohexilamina com hipoclorito de sódio por $5 \mathrm{~min}$ em temperatura ambiente. O método foi aplicado com sucesso em vinho, bolo, suco de fruta e fruta em conserva, e apresentou diversas vantagens como rapidez, simplicidade das etapas de preparação da amostra, a alta estabilidade dos produtos de derivatização e a alta seletividade da detecção. ${ }^{85}$

\section{Eletroforese capilar}

A eletroforese capilar é uma técnica baseada na separação de partículas carregadas eletricamente através da diferença de velocidade de migração dos analitos presentes na amostra. Trata-se de uma técnica que associa a necessidade de baixas quantidades de analito e reagentes com a alta eficiência e resolução na separação. ${ }^{86}$

Em 2000, com a utilização da eletrocromatografia micelar (do inglês, Micellar Electrokinetic Chromatography - MECK) com detector DAD realizou-se a determinação de três edulcorantes (acesulfame de potássio, aspartame e sacarina), conservadores e corantes em refrigerante disponíveis no comércio do Reino Unido. As amostras foram diluídas com água ultra-pura, desgaseificadas por ultrassonicação e filtradas. As condições de operação foram realizadas com tampão carbonato em $\mathrm{pH} 9,5$ e dodecil sulfato de sódio como fase micelar. ${ }^{87}$

No ano de 2006, um método utilizando eletroforese capilar para análise de oito edulcorantes (acesulfame de potássio, sacarina, aspartame, ciclamato, sorbitol, manitol, lactitol e xilitol) presentes em balas e chicletes disponíveis no comércio da República Tcheca foi desenvolvido e se mostrou rápido e eficiente. As amostras foram diluídas em água deionizada e filtradas com posterior separação por isotacoforese capilar com detector de condutividade composta por sistema de eletrólitos formado por ácido clorídrico e tris (hidroximetil) aminometano (TRIS) em pH 7,7e L-histidina e TRIS em pH 8,3. ${ }^{88}$

No Japão, pesquisadores descreveram em 2007 um método para que o ciclamato de sódio fosse determinado em alimentos como picles, geleias, frutas em calda, molho de soja e bebidas através da utilização de eletroforese capilar. O preparo das amostras foi realizado através de extração em fase sólida com fase reversa e a separação por eletroforese realizada em capilar de sílica, utilizando como eletrólitos brometo de hexadeciltrimetilamônio e sorbato de potássio em pH 7,5 e adição de padrão interno propionato de sódio. A concentração de ciclamato também foi determinada por HPLC com detector ultravioleta e a comparação entre os resultados permitiu concluir que a eletroforese se mostrou uma técnica rápida e eficiente de separação. ${ }^{89}$

A eletroforese capilar com detector de condutividade sem contato foi reportada em 2011 para determinação simultânea de quatro edulcorantes (aspartame, acesulfame de potássio, ciclamato e sacarina) em refrigerantes sem adição de açúcar e adoçantes de mesa disponíveis em comércios da cidade de Campinas-SP, no Brasil. Utilizou-se como eletrólito tris (hidroximetil) aminometano (TRIS) e histidina em pH 9,4, obtendo-se uma rápida separação dos analitos. ${ }^{90}$

\section{Espectroscopia}

A espectroscopia é definida como uma área de estudo capaz de verificar a interação entre a luz (radiação eletromagnética) e a matéria. Essa interação pode ocorrer através de emissão, absorção ou difração da radiação eletromagnética e gera espectros capazes de fornecer informações suficientes para maior compreensão da estrutura atômica e molecular. ${ }^{91}$

Alguns métodos espectroscópicos foram descritos para a determinação de edulcorantes. Em 2011, um estudo reportou a análise de ciclamato de sódio em 18 amostras de refrigerantes de baixa caloria disponíveis no Brasil através da utilização de espectrofotometria no UV/Visível a 314nm e com construção de curva de calibração a partir do padrão do analito. As amostras passaram por um processo de desgaseificação e posterior derivatização do ciclamato em $\mathrm{N}, \mathrm{N}$-diclorohexilamina. ${ }^{49}$

A espectroscopia Raman está entre as mais utilizadas na determinação de edulcorantes. Essa técnica já foi empregada em 2011 para a determinação de aspartame em adoçantes de mesa com aplicação da quimiometria para construção dos modelos de regressão parcial de mínimos quadrados (do inglês, Partial Least Squares - PLS) e regressão sobre os componentes principais (do inglês, Principal Component Regression - PCR). ${ }^{92}$ Outros estudos foram realizados para determinação de edulcorantes de forma simultânea em adoçantes de mesa líquidos ou em pó. ${ }^{93-95}$ Os métodos apresentaram alta sensibilidade ${ }^{94}$ e demonstraram que modelos PLS se mostraram mais precisos na aplicação para edulcorantes. ${ }^{93}$

Um método desenvolvido por pesquisadores mexicanos que utilizava a espectroscopia por ressonância magnética nuclear foi validado para a análise de rebaudiosídeo A, um glicosídeo de esteviol, presente em adoçantes comerciais, conforme estudo publicado em 2019. Através de uma curva de calibração, construída a partir dos grupos metila e hidroxila associados ao sinal do grupo metileno pertencente ao etilbenzeno (referência externa), foi possível calcular as concentrações do edulcorante através da área dos sinais gerados..$^{96}$

Em 2020, a espectroscopia no infravermelho por transformada de Fourier (do inglês, Fourier-Transform Infrared Spectroscopy FTIR) permitiu a determinação de cinco edulcorantes (acesulfame de potássio, aspartame, ciclamato de sódio, sacarina sódica e sucralose) em bebidas sem adição de açúcar à base de chá disponíveis no comércio da China. Espectros em 131 diferentes comprimentos de onda foram utilizados como base para tratamento dos dados por análises quimiométricas utilizando regressão PLS. O método se mostrou uma rápida e eficiente alternativa e seus resultados foram validados através de análise por HPLC com detector UV/Vis. ${ }^{97}$

Em 2021, um método desenvolvido na China baseado na utilização da espectrometria de massas com análise direta em tempo real permitiu determinar sete edulcorantes (acesulfame de potássio, aspartame, alitame, ciclamato de sódio, sacarina sódica, sucralose e neotame) em 17 amostras de bebidas alcoólicas como cervejas, licores, vinhos e uísque. O método demonstrou ter boa repetibilidade e satisfez os limites de detecção, com a vantagem de apresentar um simples preparo de amostra. Os resultados mostraram a presença de no máximo cinco edulcorantes detectados simultaneamente na mesma amostra e uma prevalência da sucralose, que apenas não foi encontrada em uma das amostras. ${ }^{98}$

\section{Análise por injeção em fluxo}

As análises por injeção em fluxo (do inglês, Flow Injection Analysis - FIA) normalmente são utilizadas para determinação de poucos analitos. Esta técnica foi desenvolvida em 1991 no Canadá e empregada para determinação de aspartame em diversos alimentos sem adição de açúcar como refrigerantes, chá gelado, geleia e doces e está baseada na análise por injeção em fluxo com biossensor. $\mathrm{O}$ sistema era composto por duas colunas, sendo uma com enzima peptidase para proceder a quebra da ligação dipeptídica e outra com 
Tabela 5. Análise comparativa das técnicas analíticas reportadas para determinação de edulcorantes

\begin{tabular}{|c|c|c|c|c|}
\hline Parâmetro & Cromatografia & Eletroforese Capilar & Espectroscopia & $\begin{array}{l}\text { Análise por Injeção em } \\
\text { Fluxo }\end{array}$ \\
\hline Preparo de Amostra & $\begin{array}{c}\text { Normalmente associada } \\
\text { com etapas de diluição, } \\
\text { homogeneização e filtração. } \\
\text { Extrações sólido-líquido e } \\
\text { líquido-líquido podem ser } \\
\text { necessárias. }\end{array}$ & $\begin{array}{c}\text { Normalmente associada } \\
\text { com etapas de diluição, } \\
\text { homogeneização e filtração. } \\
\text { Extrações sólido-líquido e } \\
\text { líquido-líquido podem ser } \\
\text { necessárias. }\end{array}$ & $\begin{array}{l}\text { Exigem preparo de amostra de } \\
\text { baixa complexidade ou nenhum } \\
\text { preparo de amostra. }{ }^{97}\end{array}$ & $\begin{array}{l}\text { Podem estar associadas } \\
\text { com etapas de diluição, } \\
\text { homogeneização e } \\
\text { filtração. }\end{array}$ \\
\hline Derivatização & $\begin{array}{c}\text { Necessária principalmente } \\
\text { para a cromatografia } \\
\text { gasosa ou quando se utiliza } \\
\text { detectores por espectroscopia } \\
\text { no ultravioleta. }{ }^{82}\end{array}$ & $\begin{array}{c}\text { A utilização de detecção } \\
\text { condutométrica faz com } \\
\text { que não seja necessária a } \\
\text { derivatização do edulcorante } \\
\text { não detectado na região do } \\
\text { ultravioleta. }^{82}\end{array}$ & $\begin{array}{l}\text { Necessária principalmente para } \\
\text { espectroscopia na região do } \\
\text { ultravioleta e visível. } .^{49}\end{array}$ & $\begin{array}{l}\text { Necessária principalmente } \\
\text { para sinais na região do } \\
\text { ultravioleta e visível. }{ }^{99}\end{array}$ \\
\hline Uso de solventes & $\begin{array}{l}\text { Utilizados no preparo da } \\
\text { amostra através de diluições } \\
\text { e como fase móvel para } \\
\text { separação. }{ }^{82}\end{array}$ & $\begin{array}{l}\text { Utilizados como eletrólitos em } \\
\text { pequena quantidade. }{ }^{82}\end{array}$ & $\begin{array}{l}\text { Utilização de solvente apenas } \\
\text { no preparo da amostra caso seja } \\
\text { necessário. } .^{97}\end{array}$ & $\begin{array}{l}\text { Solventes são necessários } \\
\text { como soluções } \\
\text { transportadoras. }{ }^{102}\end{array}$ \\
\hline Sensibilidade & $\begin{array}{c}\text { Apresentam alta } \\
\text { sensibilidade principalmente } \\
\text { quando acoplados a } \\
\text { espectrômetro de massas. }{ }^{82} \mathrm{~A} \\
\text { extração em fase sólida das } \\
\text { amostras pode aumentar a } \\
\text { sensibilidade do método. }{ }^{103}\end{array}$ & $\begin{array}{c}\text { Apresentam alta } \\
\text { sensibilidade. }{ }^{82} \mathrm{~A} \text { extração em } \\
\text { fase sólida pode aumentar a } \\
\text { sensibilidade do método. }\end{array}$ & $\begin{array}{c}\text { Apresentam alta sensibilidade } \\
\text { principalmente para } \\
\text { espectrômetro de massas. }{ }^{94}\end{array}$ & $\begin{array}{l}\text { Apresentam boa } \\
\text { sensibilidade. }\end{array}$ \\
\hline Custo & $\begin{array}{l}\text { Alto custo do equipamento e } \\
\text { da coluna de separação. }{ }^{82}\end{array}$ & $\begin{array}{l}\text { Custo reduzido do equipamento } \\
\text { em comparação com a } \\
\text { cromatografia e baixo consumo } \\
\text { de solventes. }{ }^{82}\end{array}$ & Alto custo do equipamento. ${ }^{96}$ & $\begin{array}{l}\text { Baixo custo de } \\
\text { equipamento. }{ }^{101}\end{array}$ \\
\hline Outros & $\begin{array}{c}\text { Possibilidade de } \\
\text { determinação de vários } \\
\text { edulcorantes de forma } \\
\text { simultânea. }{ }^{82}\end{array}$ & $\begin{array}{l}\text { Possibilidade de determinação } \\
\text { de vários edulcorantes de forma } \\
\text { simultânea. } .^{82}\end{array}$ & $\begin{array}{c}\text { Alguns métodos dificultam } \\
\text { a determinação de } \\
\text { vários edulcorantes } \\
\text { simultaneamente. Pode ser } \\
\text { necessária a construção } \\
\text { de um modelo através de } \\
\text { métodos quimiométricos } \\
\text { para determinação dos } \\
\text { edulcorantes. } .^{92} \text { Métodos rápidos } \\
\text { de detecção. }{ }^{13}\end{array}$ & $\begin{array}{l}\text { Apresentam instrumentação } \\
\text { simples e de baixo custo, } \\
\text { porém menor resolução em } \\
\text { relação a outros métodos } \\
\text { como a cromatografia. }{ }^{101-102}\end{array}$ \\
\hline
\end{tabular}

aspartato aminotransferase para realização da análise por injeção em fluxo, permitindo quantificar o aspartame e comparar os resultados com as informações contidas nos rótulos das amostras. ${ }^{99}$

Em estudo de 1997, a determinação turbidiométrica de ciclamato de sódio foi aplicada para refrigerantes sem adição de açúcar e adoçantes de mesa disponíveis no comércio da Espanha. O método utilizou a reação de oxidação do grupo sulfâmico do ciclamato em sulfato na presença de nitrito e posterior reação com cloreto de bário para precipitação de sulfato e medição do sinal analítico a 420nm. ${ }^{100}$ Método similar, descrito em 2005, também quantificou o ciclamato, mas após a precipitação do sulfato em sistema de fluxo de dissolução de precipitado, o analito foi dissolvido em acetato de amônia para formação de acetato que foi analisado por espectroscopia de absorção de chama. ${ }^{101}$

Por fim, no ano de 2007, um sistema de análise por injeção em fluxo acoplado a uma coluna monolítica foi proposto para determinar acesulfame de potássio, aspartame e sacarina, além de conservadores em refrigerantes tipo cola e sopas em pó disponíveis na Espanha. Utilizou-se como soluções transportadoras uma mistura de acetonitrila e água com tampão fosfato em pH 6 e mistura de metanol e água, empregando espectroscopia de arranjo de diodos como detector. Os resultados foram comparáveis aos obtidos por HPLC com detector de arranjo de diodos, porém o método apresentou menor resolução. ${ }^{102}$
A Tabela 5 apresenta uma avaliação comparativa entre as diferentes técnicas analíticas utilizadas para a determinação de edulcorantes em alimentos, discutidas neste trabalho.

\section{CONCLUSÕES}

Os edulcorantes de alta intensidade estão cada vez mais presentes na alimentação da população, seja através de adoçantes de mesa ou produtos industrializados com teor reduzido de açúcar ou sem adição de açúcar. Esses aditivos têm sido cada vez mais estudados, apresentando diversas opções para aplicação. Entretanto, a utilização desses ingredientes deve ser feita conforme preconizado pelas legislações vigentes, a fim de que a segurança dos alimentos seja garantida e que os limites máximos permitidos e a IDA sejam respeitados. Assim, faz-se necessário um controle das quantidades adicionadas em cada produto, ressaltando a importância de formas de identificar e quantificar esses aditivos. Para isso, diversos métodos analíticos já foram desenvolvidos com capacidade de realizar essa identificação, sendo que outras metodologias ainda podem ser estabelecidas. Métodos capazes de determinar vários edulcorantes de forma simultânea têm sido aplicados com sucesso, utilizando principalmente a cromatografia para separação e permitindo sua implementação como método para análises de rotina em indústrias. Métodos baseados em espectroscopia são promissores e apresentam 
vantagens relevantes, como rapidez, redução no uso de solventes e com pouco ou nenhum preparo de amostra, mas ainda estão mais restritos a técnicas por espectroscopia Raman, principalmente quando envolve análise de vários edulcorantes de forma simultânea.

\section{AGARDECIMENTO}

O presente trabalho foi realizado com o apoio da Coordenação de Aperfeiçoamento de Pessoal de Nível Superior - Brasil (CAPES) - Código de Financiamento 001.

\section{REFERÊNCIAS}

1. Instituto Brasileiro de Geografia e Estatística (IBGE); Pesquisa de Orçamentos Familiares 2018-2019: Primeiros resultados, Rio de Janeiro, 2019

2. Mukhopadhyay, S.; Goswami, S.; Mondal, S. A.; Dutta, D.; Dietary Sugar, Salt and Fat in Human Health, $1^{\text {st }}$ ed., Academic Press: Cambridge, 2020.

3. World Health Organization (WHO); Guideline: sugar intake for adult and children, Genebra, 2015.

4. World Health Organization (WHO); Proposed policy priorities for preventing obesity and diabetes in the Eastern Mediterranean Region, Cairo, 2017.

5. http://www.saude.gov.br/noticias/agencia-saude/44777-brasil-assumemeta-para-reduzir-144-mil-toneladas-de-acucar-ate-2022, acessada em setembro 2021.

6. https://www.gov.br/pt-br/noticias/saude-e-vigilancia-sanitaria/2020/10/ rotulos-de-alimentos-vao-informar-consumidor-sobre-alto-teor-deacucar-e-sodio, acessada em setembro 2021.

7. https://www.dw.com/pt-br/alemanha-vai-cortar-a\%C3\%A7\% C3\% BAcar-sal-e-gordura-em-alimentos-prontos/a-46804845, acessada em setembro 2021.

8. https://afrebras.org.br/tributacao-do-acucar-uma-estrategia-eficaz/, acessada em setembro 2021.

9. Silva, P. D.; Cruz, R.; Casal, S.; Food Control. 2021, 120, 1.

10. Acero, D.; Zoellner, J. M.; Davy, B. M.; Hedrick, V. E.; Nutrients 2020, 12,1 .

11. Agência Nacional de Vigilância Sanitária (ANVISA); Resolução RDC $n^{\circ}$ 18, de 24 de março de 2008, 2008.

12. Sharma, A.; Amarnath, S.; Thulasimani, M.; Ramaswamy, S.; Indian J Pharmacol. 2016, 48, 237.

13. Ministério da Saúde. Secretaria de Vigilância Sanitária; Portaria $n^{\circ} 540$, de 27 de outubro de 1997. Aprova o Regulamento Técnico: Aditivos Alimentares - definições, classificação e emprego, Brasília, 1997.

14. Daher, M. I.; Matta, J. M.; Abdel Nour, A. M.; Diabetes Res Clin Pract. 2019, $155,1$.

15. Chakraborty, R.; Das, A. Em Encyclopedia of Food Chemistry; Varelis, P., Shahidi, F., eds.; Elsevier: Amsterdam, 2018.

16. Agência Nacional de Vigilância Sanitária (ANVISA); Resolução da Diretoria Colegiada - RDC n. 45, de 03 de novembro de 2010.

17. Sylvetsky, A. C.; Rother, K. I.; Physiol Behav. 2016, 164, 446.

18. Tiefenbacher, K. F.; The Technology of Wafer and Waffles $I, 1^{\text {st }}$ ed., Academic Press: Cambridge, 2017.

19. Kemp, S. E. Em Optimizing Sweet Taste in Foods; Spillane, W. J., eds.; Woodhead Publishing: Sawston, 2006.

20. Sain, O. L.; Berman, J. M.; Arch. Argent. Pediatr. 1984, 82, 209.

21. Yebra-Biurrun, M. C.; Encyclopedia of Analytical Science 2013, 3, 471.

22. Otabe, A.; Fujieda, T.; Masuyama, T.; Ubukata, K.; Lee, C.; Food Chem. Toxicol. 2011, 49, S2.

23. European Food Safety Authority (EFSA); EFSA Journal 2013, 11, 3301.

24. Glória, M. B. A; Encyclopedia of Food Sciences and Nutrition, $2^{\text {nd }}$ ed., Academic Press: Cambridge, 2003.
25. Berset, J.; Ochsebein, N.; Chemosphere 2012, 88, 563.

26. Bawane, A. M.; Rekha, S. S.; Food Sci Technol. 2019, 108, 277.

27. Khattab, S. N.; Massoud, M. I.; Jad, Y. E.-S.; Bekhit, A. A.; El-Faham, A.; Food Chem. 2015, 173, 978.

28. Hutchinson, S. A.; Ho, G. S.; Ho, C. T.; Food Rev Int. 1999, 15, 249.

29. Beltrami, M.C.; Doring, T.; Lindner, J.; Food Sci Technol. 2018, 38, 181.

30. Agência Nacional de Vigilância Sanitária (ANVISA); Guia de procedimentos para pedidos de inclusão e extensão de uso de aditivos alimentares e coadjuvantes de tecnologia de fabricação na legislação brasileira, Brasília, 2015.

31. Agência Nacional de Vigilância Sanitária (ANVISA); Guia para Comprovação da Segurança de Alimentos e Ingredientes, Brasília, 2013.

32. World Health Organization (WHO); Evaluations of the Joint FAO/WHO Expert Committee on Food Additives (JECFA), Genebra, 2019.

33. https://www.fda.gov/food/food-additives-petitions/food-additive-statuslist, acessada em setembro 2021.

34. https://webgate.ec.europa.eu/foods_system/main/?event=substances. search, acessada em setembro 2021.

35. Japan External Trade Organization (JETRO); Specifications and Standards for Foods, Food Additives, etc. Under the Food Sanitation Act (Abstract), 2010

36. Price, J. M.; Biava, C. G.; Oser, B. L.; Vogin, E. E.; Steinfeld, J.; Ley, H. L.; Science 1970, 167, 1131.

37. Agência Nacional de Vigilância Sanitária (ANVISA); Esclarecimentos sobre o uso do edulcorante ciclamato em alimentos, Brasília, 2009.

38. Suez, J.; Nature 2014, 514, 181.

39. Nettleton, J. A.; Lutsey, P. L.; Wang, Y.; Lima, J. A.; Michos, E. D.; Jacobs, D. R.; Diabetes Care 2009, 32, 688.

40. Karalexi, M. A.; Mitrogiorgou, M.; Georgantzi, G. G.; Papaevangelou, V.; Fessatou, S.; J. Pediatr. 2018, 197, 128.

41. Ashwell, M.; Gibson, S.; Bellisle, F.; Nutr. Res. Rev. 2020, 33, 145.

42. Martyn, D.; Darch, M.; Roberts, A.; Lee, H.; Tian, T. Y.; Kaburagi, N.; Belmar, P.; Nutrients 2018, 10, 357.

43. Ioshi, S. H.; Dissertação de Mestrado, Universidade Estadual de Campinas, Brasil, 1992.

44. Del Bianchi, M.; Dissertação de Mestrado, Universidade Estadual de Campinas, Brasil, 2012.

45. Bannwart, G. C. M.; Tese de Doutorado, Universidade Estadual de Campinas, Brasil, 2006.

46. Barraj, L.; Scrafford, C.; Bi, X.;Tran, N.; Food Addit. Contam., Part A 2021, 38, 181.

47. https://abiad.org.br/pb/atencao-aos-adocantes-indicacoes-riscos-e-suautilizacao-na-industria/, acessada em setembro 2021.

48. Oliveira, P. B.; Franco, L. J; Arq. Bras. Endocrinol. Metab. 2010, 54, 455.

49. Petrarca, H. M.; Bonifácio M. T. E. S.; Monteiro, M.; Rev. Inst. Adolfo Lutz 2011, 70, 86.

50. Pane, D. Q.; Dias, C. B.; Meinhart, A. D.; Ballus, C. A.; Godoy, H. T.; J. Food Sci. Technol. 2015, 52, 6900.

51. Acevedo, W.; Capitaine, C.; Rodríguez, R.; Araya-Durán, I.; GonzálezNilo, F.; Pérez-Correa, J. R.; Agosin, E.; J. Sens. Stud. 2018, 33, 1.

52. Brasil; Decreto $n^{\circ} 8.592$, de 16 de dezembro de 2015. Altera o Anexo ao Decreto no 6.871, de 4 de junho de 2009, que regulamenta a Lei no 8.918, de 14 de julho de 1994.

53. McCain, H. R.; Kaliappan, S.; Drake, M. A.; J. Dairy Sci. 2018, 101, 8619.

54. Lin, S. D.; Lee, C. C.; Cereal Chem. 2005, 82, 405.

55. https://www.abimapi.com.br/cloud/PaesIndustrializadosV3.pdf, acessada em setembro 2021.

56. Silva, J. B.; Schlabitz, C., Souza, C. F. V.; Revista Brasileira de Tecnologia Agroindustrial 2010, 4, 58.

57. Benassi, V. T.; Watanabe, E.; Lobo, A. R.; Bol. Cent. Pesqui. Process. Aliment. 2001, 19, 225. 
58. Xiao Luoa, X.; Arcotb, J.; Gillc, T.; Louied, J. C. Y.; Rangan, A.; Trends Food Sci. Technol. 2019, 86, 412.

59. Struck, S.; Jaros, D.; Brennan, C. B.; Rohm, H.; Int. J. Food Sci. Technol. 2014, 49, 1963.

60. Figueiredo, L. S.; Scapin, T.; Fernandes, A. C.; Proença, R. P. C. Public Health Nutr. 2018, 21, 447.

61. Oliveira, S. Y. H.; Andrade, T. F. S.; Bragotto, A. P. A.; Em The food and beverage industry: safety, packing and management; Pilger, H. E., eds.; Nova Science Publisher: New York, 2020.

62. Agata Zygler, A.; Wasik, A.; Namiesnik, J.; Trends Anal. Chem. 2009, $28,1082$.

63. Behrens, M.; Blank, K.; Meyerhof, W.; Cell Chem. Biol. 2017, 24, 1199.

64. Herrero, M.; Reference Module in Chemistry, Molecular Sciences and Chemical Engineering 2019, 3, 64.

65. Leal, V.L.; Silva, M.R.; Lanças, F.M.; Sci. Chromatogr. 2017, 9, 117.

66. Ferrer, I.; Thurman, E. M.; J. Chromatogr. A 2010, 1217, 4127.

67. Sargaço, B. R.; Dissertação de Mestrado, Instituto Superior de Engenharia de Lisboa, Portugal, 2013.

68. Chang, C. S.; Yeh, T. S.; J. Food Drug Anal. 2014, 22, 318.

69. Wasik, A.; McCourt, J.; Buchgraber, M.; J. Chromatogr. A 2007, 1157, 187.

70. Sezgin, B.; Arli, G.; Can, N.O.; J. Food Compos. Anal. 2021, 97, 1.

71. Marques, L. M. M.; Oliveira, A. R. M.; Sci. Chromatogr. 2013, 5, 101.

72. Maldaner, L.; Jardim, I.C.S.F.; Sci. Chromatogr. 2012, 4, 197.

73. Sakai, H.; Yamashita, A.; Tamura, M.; Uyama, A.; Mochizuki, N.; Food Addit. Contam., Part A 2015, 32, 808.

74. Lorenzo, R. A.; Pena, M. T.; Fernandez, P.; Gonzalez, P.; Carro, A. M.; Food Control. 2015, 47, 43.

75. Ordoñez, E. Y.; Rodil, R.; Quintana, J. B.; Cela, R.; Food Chem. 2015, $169,162$.

76. Kubica, P.; Namieśnik, J.; Wasik, A.; J. Pharm. Biomed. Anal. 2016, 127, 184.

77. Lanças, F.M.; Sci. Chromatogr. 2010, 2, 49.

78. Baranowska, I.; Zydroń, M.; Szczepanik, K.; J. Planar Chromatogr. 2004, 17, 54.

79. Nambiar, A. P.; Sanyal, M.; Shrivastav, P. S.; J. Chromatogr. A 2018, 1572, 152 .

80. Chen, Q.; Mou, S.; Liu, K.; Yang, Z.; Ni, Z.; J. Chromatogr. A 1997, $771,135$.

81. Zhu, Y.; Guo, Y.; Ye, M.; James, F. S.; J. Chromatogr. A 2005, 1085, 143
82. Shah, R.; de Jager, L. S.; Recent Analytical Methods for the Analysis of Sweeteners in Food: A Regulatory Perspective, Food and Drug Administration Papers, 2017.

83. Zhongfu Wang, W.Q.; Nie, W.; Guo, Y.; Huang, L.; Chromatographia 2007, 66, 935 .

84. Hashemi, M.; Habibi, A.; Jahanshahi, N.; Food Chem. 2011, 124, 1258.

85. Yu. S.; Zhu, B.; Lv, F.; Li, S.; Huang, W.; Food Chem. 2012, 134, 2424.

86. Knox, H. J.; J. Chromatogr. A 1994, 680, 3.

87. Frazier, R. A.; Inns, E. L.; Dossi, N.; Ames, J. M.; Nursten, H. E.; J. Chromatogr. A 2000, 876, 213.

88. Herrmannová, M.; Křivánková, L.; Bartoš, M.; Vytřas, K.; J Sep Sci. 2006, 29, 1132.

89. Horie, M.; Ishikawa, F.; Oishi, M.; Shindo, T.; Yasui, A.; Ito, K.; J. Chromatogr. A 2007, 1154, 423.

90. Bergamo, A. B.; Fracassi J. A.; de Jesus, D. P.; Food Chem. 2011, 124, 1714.

91. Poljak, D.; Electromagnetic Fields: Environmental Exposure, $2^{\text {nd }}$ ed., Encyclopedia of Environmental Health, 2011.

92. Mazurek, S.; Szostak, R.; Food Chem. 2011, 125, 1051.

93. Duarte, L. M.; Paschoal, D.; Izumi, C. M. S.; Dolzan, M. D.; Alves, V. R.; Food Res Int. 2017, 99, 106.

94. Mignani, A. G.; Ciaccheri, L.; Mencaglia, A. A.; Verschooten, T.; Ottevaere, H.; Thienpont, H.; Procedia Eng. 2014, 87, 240.

95. Armenta, S.; Garrigues, S.; de la Guardia, M.; Anal. Chim. Acta 2004, $521,149$.

96. Paniagua-Vega, D.; Cavazos-Rocha, N.; Huerta-Heredia, A. A.; ParraNaranjo, A.; Rivas-Galindo, V. M; Waksman, N.; Saucedo, A. L.; J. Food Compos. Anal. 2019, 79, 134.

97. Wang, Y. T.; Li, B.; Xu, X. J.; Ren, H. B.; Yin, J. Y.; Zhu, H.; Zhang, Y. H.; Food Chem. 2019, 303, 1.

98. Li, X.; Li, S.; Li, B.; Li, H.; Wang, J.; Luo, Q.; Yin, X.; Food Chem. 2021, 342, 1.

99. Male, K. B.; Luong, J. H. T; Biosens. Bioelectron. 1991, 6, 117.

100. Yebra, M.; Talanta 1998, 45, 1115

101. Llamas, N. E.; Di Nezio, M. S.; Palomeque, M. E.; Band, B. S. F.; Anal. Chim. Acta 2005, 539, 301.

102. García-Jiménez, J. F.; Valencia, M. C.; Capitán-Vallvey, L. F.; Anal. Chim. Acta 2007, 594, 226.

103. Oktavirina, V.; Prabawati, N.B.; Fathimah, R.N.; Palma, M.; Kurnia, K.A.; Darmawan, N.; Yulianto, B.; Setyaningsih, W. Molecules 2021, 26,3135 . 